VOL 3 (2019) NO 4

e-ISSN : 2549-9904

ISSN : 2549-9610

INTERNATIONAL JOURNAL ON INFORMATICS VISUALIZATION

\title{
Incremental Associative Mining based Risk-Mapping System for Earthquake Analysis in Indonesia
}

\author{
Renovita Edelani", Ali Ridho Barakbah", Tri Harsono\#, Louis Nashih Uluwan Arif ${ }^{\#}$ \\ \# Department of Information and Computer Engineering, Politeknik Elektronika Negeri Surabaya, Surabaya, Indonesia \\ E-mail:redelani1410@gmail.com,ridho@pens.ac.id,trison@pens.ac.id,louisuluwan@gmail.com
}

\begin{abstract}
Indonesia is one of the largest archipelagic countries in the world that has the highest risk of an earthquake. The major causes of earthquakes in this country are plate movements and volcanic activity. Earthquakes in Indonesia has a cause and effect relationship between each province. This disaster caused severe damage including a lot of people to get killed, injured and lose their money and property. We must minimize the impact of the earthquake by forming earthquake risk mapping. The risk of seismicity in Indonesia can vary each year, so it needs to be analyzed how the changes in risk are each addition of earthquake data. This paper proposes an earthquake risk mapping system with Associative Mining based on incremental earthquake data that have the highest values of confidence rates from the seismic association between provinces in Indonesia. The system uses the Incremental Association rule method to see the trend in the value of changes in confidence for each addition of earthquake data every 5 years. This system proposes 3 main features, which are (1) Data Retrieval and Preprocessing, (2) Association Rule Mining, (3) Incremental Associative Mining based risk mapping. For the experimental study, the system used data from 1963-2018. The results show that the provinces of Maluku, North Maluku, Nusa Tenggara Timur, North Sulawesi, and Papua have an incremental association risk of an earthquake.
\end{abstract}

Keywords — Earthquake, Risk Mapping, Association rule, Incremental Data Analysis, Apriori..

\section{INTRODUCTION}

Earthquakes are caused by sudden tectonic movements in the Earth's crust. The main cause is that when tectonic plates, one rides over the other, causing orogeny to collide (mountain building), earthquakes. The largest fault surfaces on Earth are formed due to boundaries between moving plates [1]. The sudden movement of rock layers in the earth produces energy released in all directions in the form of an earthquake or seismic waves. When these waves reach the surface of the earth, vibrations can damage everything on the surface of the earth such as buildings and other infrastructure so that it can cause casualties and property. The impact of the earthquake has been tremendous because they cover a very wide area, penetrating the territorial boundaries of the state, even between continents. The nature vibrations of earthquakes that are very strong and propagate in all directions can destroy the civilian buildings, so there is no doubt that there are many victims. Even earthquakes are often followed by further natural disasters that are far more devastating in the form of landslides, soil liquefaction, and tsunami waves.

Geographically Indonesia located in a Ring of Fire area that stretches along with the Pacific plate which is the most active tectonic plate in the world. This zone contributes to almost $90 \%$ of earthquake events on earth and almost all of them are major earthquakes in the world [2]. The high seismic activity is also evident from the results of recording in the period 1900-2009 there were more than 8,000 major earthquake events with magnitude $\mathrm{M}>5.0$.

Indonesia is traversed by three meeting plates, which are the Indo-Australian tectonic plate, the Eurasian Plate and the Pacific Plate and the small plate of the Philippines. Movement of a plate can cause other plate activity. So, if an earthquake occurs in an area caused by the movement of one plate on the earth, it is very likely that an earthquake will occur in other areas that are on the path of the meeting plate. This is proven by the analysis of world geologists and the United Nations Office for Disaster Risk Reduction (UNISDR), an earthquake in Lebak, Banten with the earthquake in Alaska, United States has a relation. In its official Twitter account, as quoted by VIVA, Wednesday, January 24, 2018, UNISDR released a photo, a map of the Pacific fire ring or the Pacific Ring of Fire. In the map of the map, it is clear that there is a large red line, which shows the unity of faults or faults of rings of the earth that move and create a series of natural disasters that occur [3]. From the explanation above, it can be concluded that there are some interrelationships between earthquakes in an area with other regions in Indonesia. This seismic connection can be caused by the arrangement of the plates that cause earthquakes in 
Indonesia. So far, seismic analysis has only discussed the measurement of the frequency of earthquake events, earthquake intensity, predicting earthquakes, managing natural disasters or evacuations, etc. But no one has conducted a study of the relationship of earthquake events.

The level of earthquake risk can change over time because the earthquake event always increases every year. This trend of seismic risk needs to be analyzed so it can help calculate the risk of the province. With the analysis of the confidence value trend earthquake association, we can map it into an earthquake disaster incremental risk mapping.

This paper will explain about earthquake risk mapping system based on Incremental Association rule to see how the trend of earthquake risk each province in Indonesia. This system uses data from a combination of several providers, there are Badan Meteorologi, Klimatologi dan Geofisika (BMKG- Indonesian Meteorology Climatology and Geophysics Centre), United State Geological Survey (USGS), European-Mediterranean Seismological Centre (EMSC), and International Seismological Centre (ISC). Data are taken from 1963-2018.

\section{RELATED WORKS}

At present, there are many kinds of research on earthquakes disaster. Topics about earthquake associations with other factors, analysis of earthquake data, and earthquake risk mapping are related to this paper. We selected the topic of earthquake risk mapping as a novelty in this paper and applied Incremental Association Rule method to analysis the confidence value trend from the association between the earthquake in Indonesia. The earthquake level risk from each province is the highest confidence value from association rule.

Related to the topic of earthquake associations with other factors, Ikram and Qamar [4] predicted earthquakes by using the Association Rule method to obtain seismic rules that would later be applied to expert systems. Zhou and Gao [5] analyzed spatial association patterns between the point and line features of earthquakes use Apriori algorithm. Lee et al. [6] made an experiment to find out the characteristics of an unknown earthquake using the rule mining method of the global earthquake data association occurred. Li et al. [7] used the association rule method between abnormal variations in earthquake preliminary information and earthquake events, to get the correlations between preliminary data subjects. Edelani et al. [8] found seismic associations between several provinces in Indonesia using the association rule method.

Dealing with earthquake data analysis, Suliswati et al. $[9,27]$ calculated the earthquake density value of each cluster in Indonesia using the automatic clustering method. Barakbah et al. [10,27] analyzed cluster-oriented seismicity predictions of earthquakes in Indonesia and semantic interpretation of predicted results projected into each region. Shodiq et al. [11-14] performed earthquake predictions using the Automatic Clustering and spatial analysis of magnitude distribution to cluster the earthquake data based on the location of the source point and Neural Networks methods.

On the topic of earthquake risk mapping, Ding et al. [15] developed a system called the Disaster Earthquake Risk Estimation System (CERES for Windows) to conduct earthquake disaster risk assessments that are applied mainly in Asia based on GIS. Fariza et al. [16] visualized the seismic risk of East Java province using the Analytical Hierarchy Process method. Mapping the risk of earthquakes in Indonesia in 2015 by BNPB [2] based on the hazard index, vulnerability index and capacity index. Zhang [17] reformed earthquake maps using a fuzzy approach with the integration of fuzzy set theory, risk analysis, and geographic information system technology (GIS). Barakbah et al. [18-19] performed Big Data Analysis for earthquake risk-mapping system and create a mobile application for cluster-based visualization of earthquake distribution in Indonesia. Shodiq et al. [20] presented cluster oriented to visualize earthquake data in Indonesia.

\section{PROPOSED SYSTEM AND ORIGINALITY}

In this paper, we present a new earthquake risk mapping system based on the highest value of confidence from seismic associations between provinces in Indonesia. The system uses the Incremental Association rule method to see the trend in the value of changes in confidence for each addition of earthquake data every 5 years. We are using a primitive sliding-window technique to adding the next 5year data. We develop the system with 3 main features: (1) Data Retrieval and Preprocessing, (2) Association Rule Mining, (3) Incremental Association Risk Mapping. The system brings a new concept to see the trend of earthquake risk level based on the result of Association Rule Mining. The earthquake data was taken from 1963 to 2018 from several sources of earthquake data providers there are Badan Meteorologi, Klimatologi dan Geofisika Indonesia (BMKG), United States Geological Survey (USGS), EuropeanMediterranean Seismological Center (EMSC), and International Seismological Center (ISC). This earthquake mapping system will provide information about graphs of changes in earthquake risk conditions for each province in Indonesia. Each province will have different characteristics of changes in earthquake risk values every 5 years from the method calculations performed.

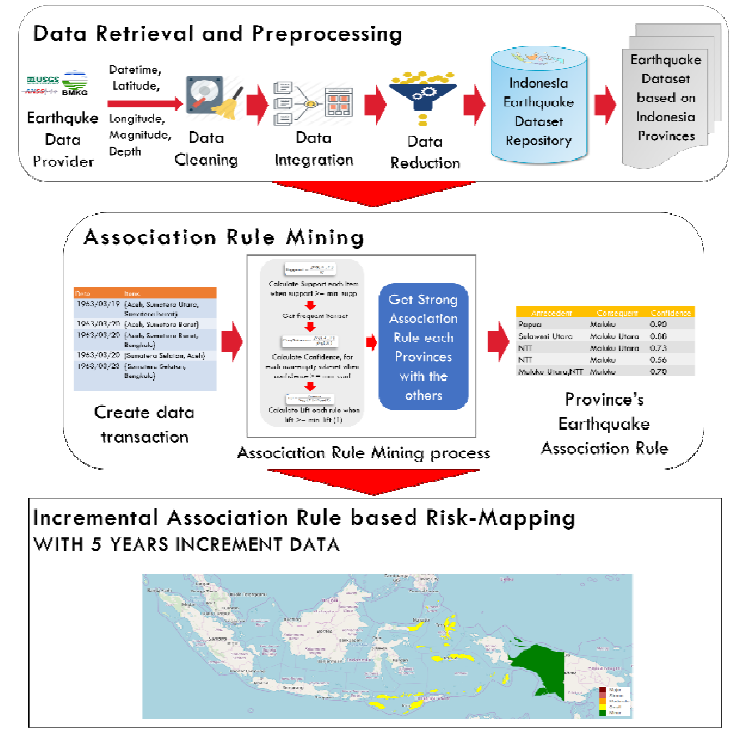

Fig. 1 Our Proposed System Design for Incremental Association RiskMapping 
Fig. 1 shows the design of our proposed system. The first stage is the process of retrieving data and preprocessing the data so that it is ready to be processed. The next step is the Association rule mining process, which aims to find earthquake association rules for each province in Indonesia that produce antecedent provinces and consequent provinces with their confidence values. The last step is displaying earthquake risk mapping based on the highest confidence values which are categorized into three, which are red means the risk value is $\geq 0.7$ with a high level of risk, yellow is between 0.5 and 0.7 with a moderate-risk level and green with risk $<0.5$ with a low-risk level. Also, there is a graph of risk trends from 1963-2018.

\section{A. Data Retrieval and Preprocessing}

At this stage, data will be taken from several earthquake data providers and will be processed in such a way in several stages, namely data cleaning, integration, and reduction as well as determining the provincial location of each data so that the data is ready for use at the next stage.

Earthquake dataset is a collection of earthquake data that has attributes such as latitude, longitude, magnitude, depth, and time of the earthquake. Many sources provide earthquake data, such as ANSS (Advanced National Seismic System) or USGS (United States Geological Survey), BMKG (Meteorology, Climatology, and Geophysics Indonesia), European-Mediterranean Seismological Center (EMSC), and International Seismological Center (ISC). This study uses data from earthquake data providers above to be used as research data. The earthquake data to be taken starts from 1963 - 2018, is between latitude -11 - 6 and longitude 94.0 - 142.0 .

TABLE I

FORMAT OF EARTHQUAKE DATASET

\begin{tabular}{|l|l|l|l|l|l|}
\hline Date Time & Lat. & Long. & Dep. & Mag. & Province \\
\hline $\begin{array}{l}\text { 01/01/2018 } \\
\text { 00:01:17.77 }\end{array}$ & - & 127.29 & 0.0 & 3.3 & NTT \\
\hline $\begin{array}{l}\text { 01/01/2018 } \\
\text { 00:37:12.18 }\end{array}$ & 3.79 & 127.19 & 0.0 & 3.6 & $\begin{array}{l}\text { North } \\
\text { Sulawesi }\end{array}$ \\
\hline $\begin{array}{l}\text { 01/01/2018 } \\
\text { 00:52:30.98 }\end{array}$ & - & 123.28 & 127 & 4.5 & $\begin{array}{l}\text { Central } \\
\text { Sulawesi }\end{array}$ \\
\hline $\begin{array}{l}\text { 01/01/2018 } \\
\text { 02:47:53.65 }\end{array}$ & -1.4 & 120.47 & 10 & 2.4 & $\begin{array}{l}\text { Central } \\
\text { Sulawesi }\end{array}$ \\
\hline $\begin{array}{l}\text { 01/01/2018 } \\
\text { 03:03:26.14 }\end{array}$ & - & 117.42 & 24 & 2.4 & NTB \\
\hline
\end{tabular}

The datasets obtained from the data provider aren't all complete and there are missing values such as the magnitude and depth of the earthquake. Data that loses magnitude and depth will be immediately deleted or not used. The data provided by each earthquake data provider is very diverse and has its characteristics. This process changes the date and time format of each dataset to dd/MM/yyyy where the date and time are one column. Data taken has attributes date, time, latitude, longitude, depth, and magnitude. After that, all data is combined into one large dataset. the process of data reduction or reduction of data that has been combined from all sources. In this process, it involves the process of calculating the distance between data using Dynamic Time Warping to find out which data has the same earthquake point source (has a small distance value) and is selected into one data only.

To determine the province of each data using the latitude and longitude. The process is carried out by calculating the closest distance from the latitude and longitude points of the earthquake object to the midpoint of each province, after taking three provinces closest to the point of the earthquake object, calculate the distance of the earthquake object with the edge of the three closest provinces, make the province with the distance of the closest edge and earthquake point as the province of the earthquake object.

\section{B. Association Rule Mining}

Association Rule is one of the main techniques or procedures in Market Basket Analysis to find facts about the relationship between items in a data set and display in the form of Association Rule [21]. Association Rule will find certain patterns that associate one data with another. To find the Association Rule from a data set, the first step that must be done is to look for frequent itemset first. A frequent itemset is a set of items that often appear simultaneously. While the itemset itself is a group of items. Itemset with the number of items $\mathrm{k}$ is called $\mathrm{k}$-Itemset. After all the frequent itemset patterns are found, then look for associative rules or linkages rules that meet the predetermined requirements.

The Apriori algorithm is an algorithm that performs frequent itemset searches using the Association Rule technique [22]. This algorithm was introduced by Agrawal and Srikant in 1994. Apriori was designed to operate a database containing transaction data. The Apriori algorithm uses the knowledge of the frequency of previously known attributes to process further information. The Apriori algorithm determines which candidates might appear by paying attention to minimum support and minimum confidence.

Association Rule requires a variable size that is determined by the user to determine the extent to which or how much output the user wants. Support and confidence are a measure of the trust and usefulness of a pattern that has been found [23]. While the Lift ratio is a measure to determine the strength of the association rule that has been formed, the minimum lift value is 1 [24].

Support is the percentage value of a combination of items in the database. Support formulas are as follows:

$\operatorname{supp}(A)=\left(\frac{\text { number of transactions containing } A}{\text { Total transaction }}\right)$

While confidence is the value of certainty, particularly the strong relationship between items in an apriori. Confidence can be searched after the pattern of frequency of appearance of an item is found. The formula for calculating confidence is as follows:

$$
\text { Confidence }(X \rightarrow Y)=P(Y \mid X)=\frac{\operatorname{support}(X \cup Y)}{\operatorname{support}(X)}
$$

Lift is a measure that shows how important or useful a rule and ranking of the rule. Lifts are measured based on their respective antecedent and consequent support.

$$
\operatorname{Lift}(X \rightarrow Y)=\frac{\operatorname{confidence}(X \rightarrow Y)}{\operatorname{supp}(Y)}
$$


In this paper, the purpose of using this method is to get the facts about the earthquake relationship between each province in Indonesia. The minimum value of support inputted on the parameter is a frequent itemset determinant of earthquakes in each province. The confidence value obtained is used as a percentage value of the possibility of an earthquake occurring in other provinces and later this confidence value is used as a basis for obtaining an earthquake risk value.

To measure the value of confidence of the rules that have been obtained, use measurements using Lift. The lift will give the value of the strength of the association from the earthquake in each province in Indonesia. Lift values that are greater than 1 are considered to be valid rules or show the interrelations of the provinces.

\section{Incremental Association Rule based Earthquake Risk Mapping}

The earthquake risk mapping system is based on the results of the Incremental Association Rule Mining. Earthquake data certainly increases every day, so any rule changes can occur with each addition of the data. Therefore, we need a method to see the trend of rule changes that occur. The Incremental Association Rule Mining method provides a solution to this. In this study, the method used is still primitive by repeating the mining process from old data added with new data.

This study uses a primitive sliding-window method where earthquake data will continue to increase for a period of 5 years. The transaction database into several partitions, the SWF (sliding-window filtering) algorithm [25] employs a filtering threshold to deal with the candidate itemset generation. Under SWF, the cumulative information of mining previous partitions is selectively carried out in the direction of candidate itemsets for the subsequent partitions. Because it is still the primitive incremental association rule to calculate the calculation of confidence values one year it must be recalculated from the start.

The concept of incremental mining on transaction databases in further illustrated in Fig. 2 [26]. For a dynamic database, old transactions $\left(\boldsymbol{\Delta}^{-}\right)$are deleted from the database $\mathrm{D}$ and new transactions $\left(\Delta^{+}\right)$are added as time advances. Naturally, $\Delta^{-} \subseteq D$. Denote the updated database by $D^{\prime}$, $D^{\prime}=\left(D-\Delta^{-}\right) \cup \Delta^{+}$. We also denote the set of unchanged transactions by $D^{-}-D-\Delta^{-}$.

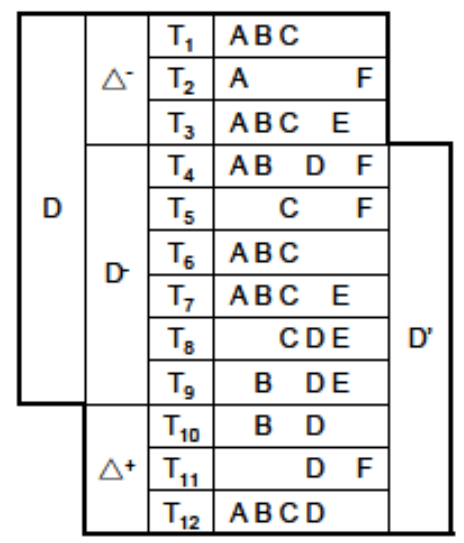

Fig. 2 An Illustrative transactional database for incremental mining [26]
This risk mapping uses data from 1963-2018 because in the year before 1963 the association rule was not found. As an example in 1963-2018 with 5 years period experiments, the mapping displayed was a risk for the period of the year and also displayed a graph of confidence values in the period 1963-1967, 1963-1972, 1963-1977, ... 1963-2018.

The risk value is based on the highest confidence values which are categorized into three, which are red means high level of risk with $\geq 0.7$, yellow is moderate-risk level with value between $0.5 \leq$ risk $<0.7$ and green is low-risk level bellow 0.5 .

\section{EXPERIMENTAL RESULT}

In this section, we explain the experimental results of our earthquake risk mapping system in Indonesia based on Incremental Association Rule mining to observe the trends of confidence value.

\section{A. Data Retrieval and Preprocessing}

The process of finding earthquake association rules from provinces in Indonesia uses the Association Rule method. The first step that must be done is to form transaction data. Earthquake transaction data is formed based on the determined n-day earthquake event. For example, data transactions for 7 earthquake days means that earthquakes that occur for 7 days will be made into one transaction data.

TABLE II

EARTHQUAKE DATA TRANSACTION FORMAT

\begin{tabular}{|c|l|}
\hline Date & \multicolumn{1}{c|}{ Items } \\
\hline $1963 / 03 / 19$ & $\{$ Aceh, North Sumatera, West Sumatera $\}$ \\
\hline $1963 / 03 / 20$ & $\{$ Aceh, West Sumatera $\}$ \\
\hline $1963 / 03 / 20$ & $\{$ Aceh, West Sumatera, Bengkulu $\}$ \\
\hline $1963 / 03 / 20$ & (South Sumatera, Aceh $\}$ \\
\hline $1963 / 03 / 23$ & $\{$ South Sumatera, Bengkulu $\}$ \\
\hline
\end{tabular}

The next step is the Association Rule process to get rules from specified transaction data. The step is to find support values from each province, after determining the first combination of 2 provinces, rediscovering the second combination support value for 3 provinces, do that until there are no more combinations for each province, then calculate the confidence value of provincial association.

TABLE III

EARTHQUAKE ASSOCIATION RULE RESUlT

\begin{tabular}{|l|l|l|}
\hline \multicolumn{1}{|c|}{ Antecedent } & \multicolumn{1}{c|}{ Consequent } & Confidence \\
\hline Papua & Maluku & 0.90 \\
\hline North Sulawesi & North Maluku & 0.88 \\
\hline NTT & North Maluku & 0.73 \\
\hline NTT & Maluku & 0.56 \\
\hline North Maluku,NTT & Maluku & 0.70 \\
\hline
\end{tabular}

Primitive Incremental association rule mining is done by repeating the mining process from the beginning of the experiment year. In the period of the second incremental year, data from 1963-1967 were added to the data from 1968-1972 (5 years of data addition). So, the mining process began from 1963-1972. This primitive method requires a very long computational time. 


\section{B. Risk-Mapping based Incremental Association}

The results of the 5-year incremental association mapping analysis, it was found that several provinces appeared to have earthquake risk in the specified periods. The Association Rule parameter set for this experiment is the minimum support 0.1 , minimum confidence 0.1 , minimum lift 1 and the earthquake event transaction that occurs for 7 days. An example of earthquake association risk mapping based on the value of the greatest confidence illustrated in Fig. 3 and Fig. 4.

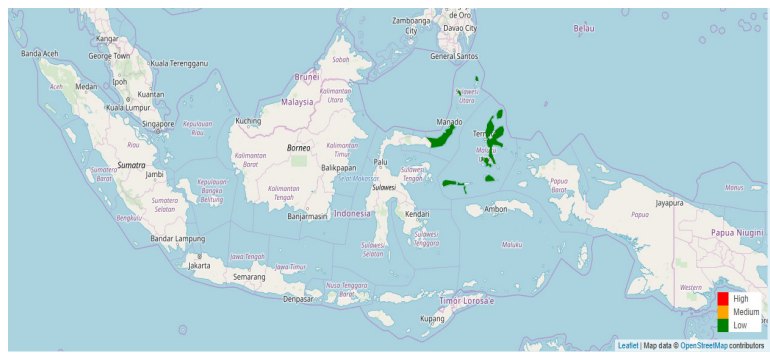

Fig. 3 Earthquake Association Risk Mapping period 1963-1967

In the period 1963-1967, two provinces were found to have earthquake risk levels illustrated in Fig. 3. North Maluku had a low-risk level with a value of confidence of 0.407 obtained from North Sulawesi. North Sulawesi with a low level of risk was obtained from North Maluku province with a confidence value of 0.376

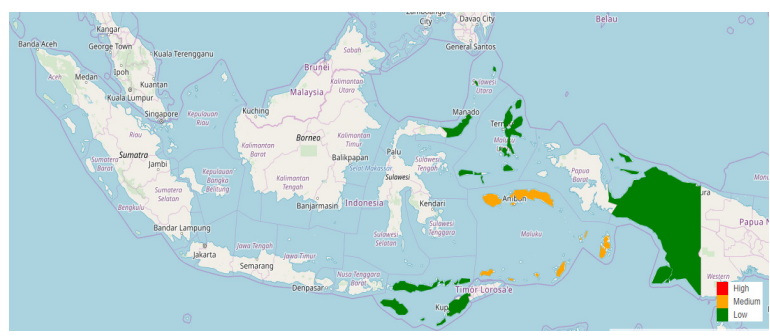

Fig. 4 Earthquake Association Risk Mapping period 1963-2018

In this twelfth incremental year period illustrated in Fig. 4, data from 1963-2017 were added to data from 2018 (1 year of addition) and risk mapping was generated for five provinces namely Maluku (moderate), North Maluku (low), NTT (low), North Sulawesi (low), and Papua (low). North Sulawesi has a low-risk level obtained from North Maluku with a confidence value of 0.38 . North Maluku has a lowrisk level obtained from the largest confidence value of 0.45 obtained from North Sulawesi, while it also has a seismic relationship with NTT with a confidence value of 0.44 . Maluku has moderate risk levels obtained from NTT with confidence values of 0.51 and Papua with confidence values of 0.49. Papua has a low-risk level obtained from Maluku with a confidence value of 0.29 . NTT has a low seismic risk level obtained from Maluku with a confidence value of 0.24 and northern Maluku with a confidence value of 0.24

The changes in risk level from confidence value will be analyzed, where the earthquake data will be added every 5 years from period to period. Provinces found in this risk mapping are Maluku, North Maluku, NTT, North Sulawesi, and Papua.

\section{1) Maluku}

Maluku Province has fluctuated the value of risk or level of risk from year to year. The initial risk of this province was low in the period 1963-1972. This risk was increasingly rising to become moderate-risk when data increases to the period 1963-1987 until 1963-1997 period. However, the confidence value began to drops in 2002. And it has increased again at the 2018. With the addition of data for one year, the risk level is stable. This province earthquake risk was found in 11 of the 12 years of the trial period. North Sulawesi province only once provided a seismic risk in 1972 with a confidence value of 0.424 or low risk.

In the next year trial period, NTT province contributed a great deal of earthquake risk to the province. The level of risk given is low and moderate. The highest risk value is given by NTT in 1997 with a risk value of 0.556 or moderate-risk. Fig. 5 illustrates a graph of confidence value trends of earthquake association between Maluku and NTT.

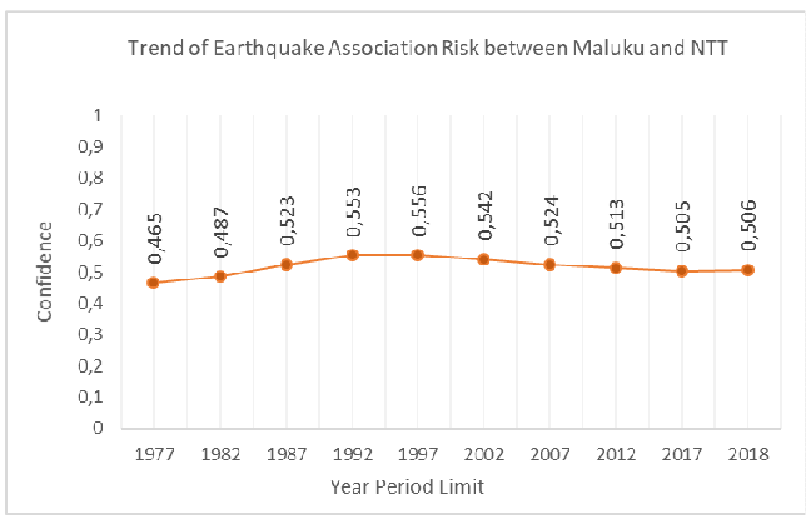

Fig. 5 Graph of confidence (risk) value trend between Maluku and NTT

Papua province also provides seismic risk for Maluku. This province was discovered in 4 years of trials there are 1992, 2007, 2017 and 2018. The risks given were low and moderate. Fig. 6 shows the confidence value graph from the association between Maluku and Papua.

Trend of Earthquake Association Risk between Maluku and Papua

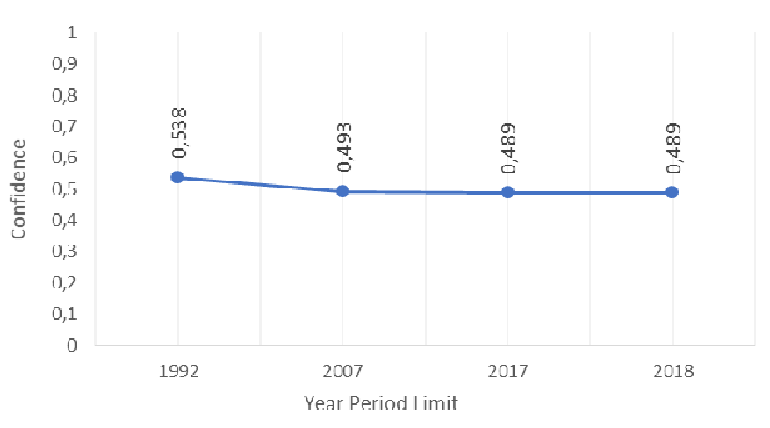

Fig. 6 Graph of confidence (risk) value trend between Maluku and Papua

\section{2) North Maluku}

North Maluku Province has a low-risk level during the trial of adding earthquake data. North Sulawesi Province always appears as a province that has an impact on the risk of each addition of data and increases and decreases the 
value of confidence. NTT Province was found to have a seismic relationship with this province in the period 19631997. In this province, there is no risk giving provinces that have disappeared due to additional data. The value of confidence in relations with this province is mostly worth 0.4. This province was found in all 12 years of the trial period. The risk of earthquakes in this province was always given by North Sulawesi. The risk was in a low category. The highest risk value was obtained in 1972 with a value of 0.476.Fig. 7 illustrates a chart of confidence value trends from 1963-2018 between North Maluku and North Sulawesi.

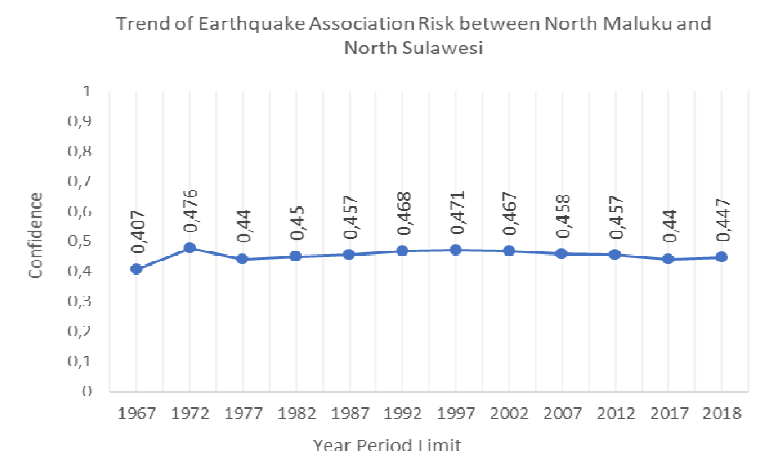

Fig. 7 Graph of confidence (risk) value trend between North Maluku and North Sulawesi

NTT province also poses earthquakes association risks. The risk arises in the 6-year trial period. The level of risk provided is low and stable. Fig. 8 shows the trend graph of confidence value between North Maluku and NTT.

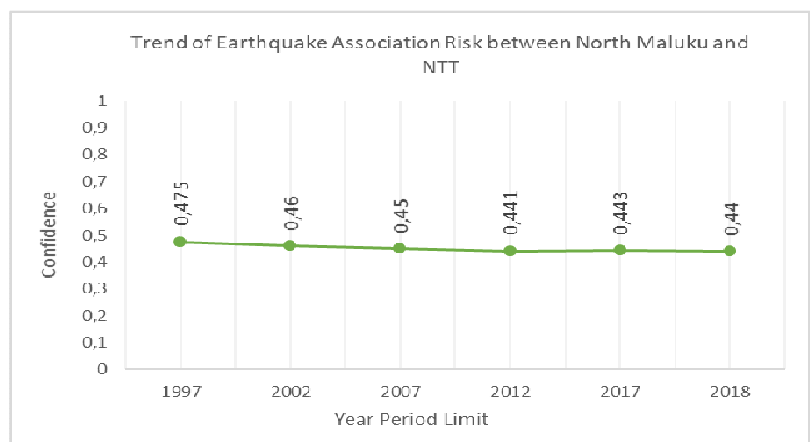

Fig. 8 Graph of association risk value trend between North Maluku and NTT

\section{3) Nusa Tenggara Timur (NTT)}

NTT Province has a low level of risk during the incremental trial of adding earthquake data. The risk value also increases and decreases but is still at a low-risk level. Maluku Province has always emerged as an earthquake riskgiving province in NTT province. North Maluku Province began to be found to have seismic associations at the 1997 period limit year. North Sulawesi Province only appeared in the period 1963-1992. The value of confidence found in this province is only around 0.2 . This province was found in 10 of the 12-year limits of the trial period.

The relationship of earthquake risk between NTT and North Sulawesi was only found in 1992 with a risk value of 0.256. Most of the earthquake risk comes from Maluku. The risk given was also relatively low and no significant changes occur. Fig. 9 shows the line graph of confidence value changes each trial period from 1963-2018 between NTT and Maluku.

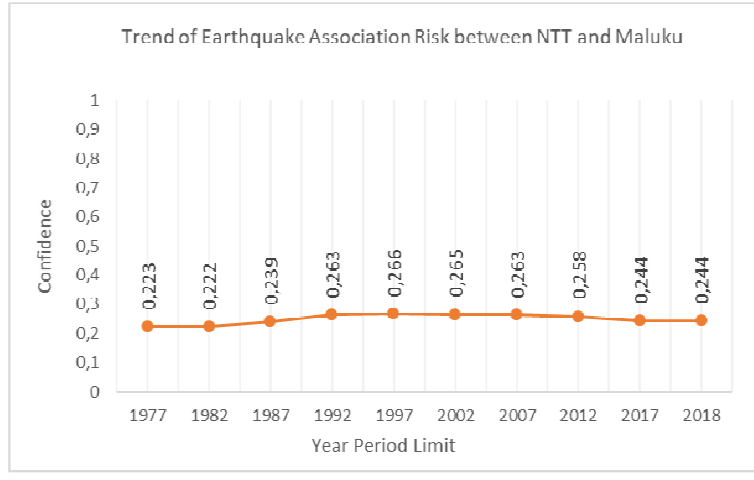

Fig. 9 Graph of association risk value trend between NTT and Maluku

North Maluku province also contributes to earthquake risk in this province. The risk was given only in 6 years of trial with a low-risk value. Fig. 10 illustrates the trend graph of confidence values between NTT and North Maluku.

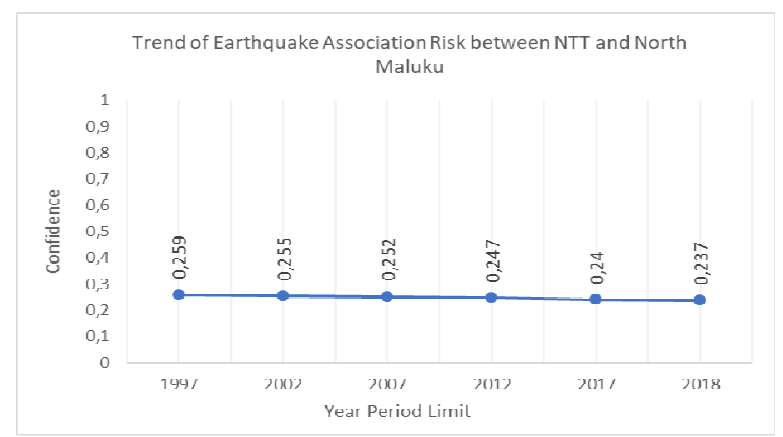

Fig. 10 Graph of association risk value trend between NTT and North Maluku

\section{4) North Sulawesi}

North Sulawesi Province has a low-risk level. The increase in risk level occurred at the period 1963-1972 and the period 1963-1992, after which it drops again. North Maluku Province always appears as a provider of earthquake risk in North Sulawesi province. NTT Province was found once in the period 1963-1992 and Maluku in the period 1963-1972. The value of confidence in the seismic relationship between these provinces and North Sulawesi is between $0.3-0.4$. This province was found in all 12 years of the trial period.

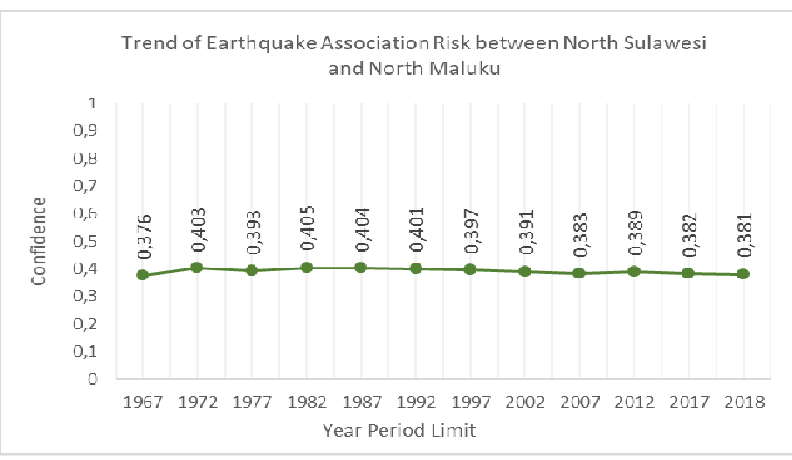

Fig. 11 Graph of association risk value trend between North Sulawesi and North Maluku 
NTT only once gave earthquake risk in 1992 with a risk value of 0.368 . The Province of Maluku also only once provided risks with the same risk value in 1972. Almost all earthquake risks obtained from North Maluku. Level of risk given at a low level. The greatest risk value was obtained in 1982 with a value of 0.405 . Fig. 11 shows a graph of the earthquake confidence value between North Sulawesi and North Maluku.

\section{5) Рариа}

Papua Province has a low-risk level at all years of risk discovery. This overall risk is caused by the impact of the earthquake in Maluku province with a rounded risk value of 0.3 . The risk in this province from period 1963-1992 has decreased to the period 1963-2017. Papua Province was not found in the twelve data additions trials, only in the period 1963-1992, 1963-2007, 1963-2017 and 1963-2018. Fig. 12 shows the confidence value trend from the earthquake association between Papua with Maluku Province.

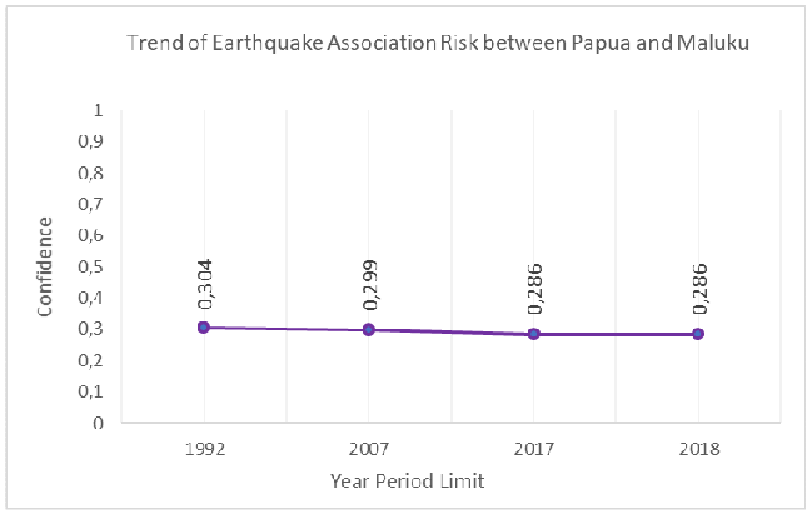

Fig. 12 Graph of association risk value trend between Papua and Maluku

\section{INDONESIA EARTHQUAKE INCREMENTAL RISK ANALYSIS}

From the experiments that have been carried out, it can be analyzed trends in earthquake risk in five provinces in Indonesia, there are Maluku, North Maluku, NTT, North Sulawesi and Papua. According to Badan Nasional Penanggulangan Bencana (BNPB-National Disaster Management Authority), five provinces located in an earthquake-prone zone [28]. Maluku and North Maluku provinces have many active faults which can cause earthquakes. The results of this study also produce the same statements. Risks in Maluku and North Maluku province have moderate risks and always occur during the period trial year.

Meanwhile, Sulawesi Island is structured of an active geological structure and has 48 earthquake sources. This study also proved that the risk of seismicity in North Sulawesi is low but it often happens where it is always found in every trial year. In this study, Papua has a low seismicity risk. This risk is obtained from Maluku. This is proven by the complex geological conditions of Maluku and Papua which have 79 sources of the earthquake also causing the province to have a risk of an earthquake. The risk of earthquakes in Nusa Tenggara Timur is also proven by the existence of 75 sources of earthquakes in the Nusa Tenggara region to the Sea of Banda. Each province giving and receiving seismic risk has a geological structure that causes earthquakes. Seismic activity always occurs in each period of the year as evidenced by this study where the risk can fluctuate according to the increase in earthquake events each year.

\section{CONCLUSIONS}

We have presented a new earthquake risk mapping system based on Incremental Association Rule mining. Incremental Association Rule based Risk-Mapping in addition to 5-year earthquake data aims to see the effect of adding data on the value and level of seismic risk in a province. This function produces a maximum risk value for a province only at the moderate level in the Maluku province in the period 19631992, after that period the risk has decreased again. The addition of data is very influential on the outcome of each province's risk. The provinces are found in each period of the addition of data and some disappear after it reappears. With this method, only 5 provinces were found to be at risk, which are Maluku, North Maluku, NTT, North Sulawesi and Papua. Only the provinces of North Maluku and North Sulawesi always appear in each trial period. The value of confidence found with this method is small due to the increasing frequency of data.

\section{REFERENCES}

[1] Sunarjo, M. T. Gunawan dan S. Pribadi, Gempabumi Edisi Populer, Jakarta: Badan Meteorologi Klimatologi dan Geofisika, 2012.

[2] L. Kurniawan, B. W. Widjaja and W. Rampangilei, Risiko Bencana Indonesia (RBI), Jakarta: BNPB (Badan Nasional Penanggulangan Bencana), 2016

[3] B. A. Wicaksono, "Ternyata Gempa Jakarta dan Gempa Amerika Berkaitan," Viva, 24 January 2018. [Online]. Available: https://www.viva.co.id/berita/nasional/1000084-ternyata-gempajakarta-dan-gempa-amerika-berkaitan. [Accessed 10 April 2019]

[4] A. Ikram and U. Qamar, "Developping an expert system based on association rules and predicate logic for earthquake prediction," Knowledge-Based Systems, Vol. 75, No. C, pp. 87-103, 2015.

[5] Y. Zhou and L. Gao, "An Apriori Based Algorithm Associated Point Line Pattern Applied in Seismic Spatial Data," in International Conference on Artificial Intelligence: Technologies and Applications, 2016.

[6] J. A. Lee, J. Han and K. H. Chi, "Mining quantitative association rule of earthquake data," in International Conference on Hybrid Information Technology, 2009.

[7] Z. Li, J. An, H. Yin, Y. Tian and W. Yu, "Study on Association Rules Between Earthquake Event and Earthquake Precursory Information Anomalies," in International Congress on Image and Signal Processing, BioMedical Engineering and Informatics, 2018.

[8] R. Edelani, A. R. Barakbah, T. Harsono and A. Sudarsono, "Association Analysis Of Earthquake Distribution in Indonesia For Spatial Risk Mapping," in International Electronics Symposium on Knowledge Creation and Intelligent Computing (IES-KCIC), 2017.

[9] A. E. Suliswati, A. R. Barakbah, T. Harsono and Y. Setyowati, "Earthquake density measurement using Automatic Clustering," in Knowledge Creation dan Intelligent Computing (KCIC), 2014.

[10] A. R. Barakbah, T. Harsono and A. Sudarsono, "Automatic Clusteroriented Seismicity Prediction Analysis of Earthquake Data Distribution in Indonesia," International Journal on Advanced Science Information Technology, Vol. 9, No. 2, pp. 587-593, 2019.

[11] M. N. Shodiq, D. H. Kusuma, M. G. Rifqi, A. R. Barakbah and T. Harsono, "Neural Network for Earthquake Prediction Based on Automatic Clustering in Indonesia," Internation Journal onf Informatics Visualization, Vol. 2, No. 1, pp. 38-43, 2018.

[12] M. N. Shodiq, A. R. Barakbah and T. Harsono, "Spatial Analysis of Earthquake Distribution with Automatic Clustering for Prediction of Earthquake Seismicity in Indonesia," in The Fourth Indonesian- 
Japanese Conference on Knowledge Creation and Intelligent Computing (KCIC), 2015.

[13] M. N. Shodiq, D. H. Kusuma, M. G. Rifqi, A. R. Barakbah and T. Harsono, "Spatial Analisys of Magnitude Distribution for Earthquake Prediction using Neural Network Based On Automatic Clustering in Indonesia," in 2017 International Electronics Symposium on Knowledge Creation and Intelligent Computing (IES-KCIC), 2017.

[14] M. N. Shodiq, D. H. Kusuma, M. G. Rifqi, A. R. Barakbah and T. Harsono, "Adaptive Neural Fuzzy Inference System and Automatic Clustering for Earthquake Prediction in Indonesia," International Journal on Informatics Visualization, Vol. 3, No. 1, pp. 47-53, 2019.

[15] X. Ding, X. Wang, L. Wang and Y. Zheng, "The development of catastrophe earthquake risk estimation system based on GIS," in IEEE International Geoscience and Remote Sensing Symposium, 2011.

[16] A. Fariza, N. P. Abhimata and J. A. N. Hasim, "Earthquake Disaster Risk Map in East Java, Indonesia, using Analytical Hierarchy Process - Natural Break Classification," in Knowledge Creation and Intelligent Computing (KCIC), 2016.

[17] J. Zhang, "A fuzzy approach for reforming earthquake map," in International Conference of the North American Fuzzy Information Processing Society, 2003.

[18] A. R. Barakbah, T. Harsono, A. Sudarsono and R. A. Aliefyan, "Big Data Analysis for Spatio-Temporal Earthquake Risk-Mapping System in Indonesia with Automatic Clustering," in The International Conference on Big Data Research (ICBDR) 2017, 2017.

[19] A. R. Barakbah, T. Harsono, A. Sudarsono and M. Askari, "A Mobile Application for Cluster-based Visualization of SpatioTemporal Earthquake Data Distribution in Indonesia," in 2017 International Electronics Symposium on Knowledge Creation and Intelligent Computing (IES-KCIC), 2017.
[20] M. N. Shodiq, A. R. Barakbah and T. Harsono, "Cluster Oriented Spatio Temporal Multidimensional Data Visualization of Earthquake in Indonesia," EMITTER International Journal of Engineering Technology, Vol. 3, No. 1, pp. 53-67, 2015.

[21] I. Budi, S. Bressan and N., "Co-Reference Resolution for Indonesian Languange Using Association rules," in The Eighth International Conference on Information Integration and Web-based Applications Services, 2006.

[22] R. Agrawal and R. Srikant, "Fast Algorithms for Mining Association Rule," in IBM Almaden Research Center, 1994.

[23] J. Han, M. Kamber and J. Pei, Data Mining: Concepts and Techniques Edition 3, Waltham: Morgan Kaufmann , pp. 243-256, 2000.

[24] R. J. R. Bayardo, "Mining the Most Interesting Rule," in KDD '99 Proceedings of the fifth ACM SIGKDD international conference on Knowledge discovery and data mining, 1999.

[25] C.-H. Lee, C.-R. Lin and M.-S. Chen, "Sliding-Window Filtering: An Efficient Algorithm for Incremental Mining," in ACM 10th International Conference on Information and Knowledge Management, 2001.

[26] W.-G. Teng and M.-S. Chen, Incremental Mining on Association Rules, Taipei:Department of Electrical Engineering, National Taiwan University, pp. 1-38.

[27] A. R. Barakbah, T. Harsono, A. Sudarsono, Pemanfaatan Klasterisasi Otomatis untuk Analisis Gempa, Surabaya: Revka Prima Media, 2019

[28] Tim Pusat Studi Gempa Nasional, Peta Bahaya dan Sumber Gempa Indonesia Tahun 2017, Bandung: Kementrian Pekerjaan Umum dan Perumahan Rakyat, 2017. 